P188 (continued)

also suggest that the class needs to be more accessible, shorter, and consist of activities that require less typing.

Funding: None

\section{P189 Building Healthier Kindergarten Students Through Nutrition Education}

Trina Robertson, MS, RD, trinar@dairycouncilofca.org, Dairy Council of California, 1418 North Market Boulevard, Suite 500, Sacramento, CA 95834;

A. Larsen, PhD; Y. Liao, PhD, Postdoctoral Fellow at MD Anderson Cancer Center; G. F. Dunton, University of Southern California; J. Hu, PhD; J. Alberts, PhD, Dairy Council of California

Objective: The goal of the Building a Healthy Me (BHM) program is to promote a healthy diet, defined as one that includes nutrient-rich foods. This provides positive messages of what students can eat, not what is forbidden and encourages sensible eating patterns that can be maintained long term.

Target Audience: California Kindergarten students and their families. Program delivered in English and Spanish.

Theory, Prior Research, Rationale: The program is based on an integration of the Health Belief Model and Social Cognitive Theory. Early childhood is an ideal time to solidify a strong foundation of good nutrition. School classrooms allow for a large reach of students and many parents are actively involved in their children's school work.

Description: This 8-unit classroom-based nutrition education program covers food group classifications, healthy snacks, and the importance of breakfast. Family homework builds on key concepts to encourage dialogue and improved home food environment.

Evaluation: A quasi-experimental design assessed changes in the outcomes, with pre- and post-surveys completed in the intervention group in 2013-14 school year.

Conclusions and Implications: Results from the student surveys showed significant improvements in students' nutrition knowledge for all of the content areas tested after receiving the BHM lessons. Students in the intervention classrooms had a greater percentage of correct nutrition knowledge answers on the post-survey than students in the control classrooms. This suggest that the BHM program was most effective at improving kindergarten students' nutrition knowledge.

Funding: Dairy Council of California

\section{P190 Implementation of a Nutrition} \section{Education Program in Primary Schools in an} Area With Patrimonial Poverty in Monterrey, Mexico

Luanda Saltijeral, MA, luanda.saltijeral@savethechildren. org, Save the Children, Francisco sosa No. 30 Col. Villa Coyoacan Del Coyoacan, Mexico, DF, C.P. 04000, Mexico; M. P. Herrera
Objective: To implement an educational intervention program for the promotion of healthy lifestyles through the improvement of nutrition practices in children of primary schools in an area with patrimonial poverty in Monterrey, Nuevo Leon, Mexico.

Design, Participants, and Intervention: The implementation was carried out during 2015 in 6 primary schools with 1450 children and 316 parents through the following activities: 9 school workshops, 5 workshops for parents and school community, children's clubs for a healthy lifestyle and evaluation of the nutritional status (weight and height) of 820 students.

Outcome Measures and Analysis: A pre and post intervention assessment was performed, using a Knowledge, Attitudes and Practices survey (KAP). The data analysis was descriptive.

Results: We found a 3.5\% higher prevalence for obesity in children participating when comparing with the prevalence reported at state level; however, a decrease in the daily consumption of two or more sugar-sweetened beverages at school was found (51\% vs. 9\%). The consumption of two or more fresh vegetables a day increased from $27 \%$ to $47 \%$ after the intervention and the consumption of foods with high energy density decreased from $48 \%$ to $40 \%$. Additionally, 5 children's clubs for a healthy lifestyle were formed and activities in favor of healthier school environments were carried out by each one.

Conclusions: The intervention resulted in improved nutrition-related knowledge in children participating in the program, and therefore, better tools that allow them to select healthier foods and to be transmitters of information to their families.

Funding: FEMSA

\section{P191 Childcare Teacher Perceptions of Their Role in Child Health and Nutrition}

Susan Sisson, PhD, RD, LDN, CHES, FACSM, susan-sisson@ ouhsc.edu, University of Oklahoma Health Sciences Center, 1200 North Stonewall Avenue \#3057, Oklahoma City, OK 73117; C. L. Smith, MS; M. Cheney, PhD

Objective: Examine childcare teacher's perceptions of their role in child health and obesity prevention specifically pertaining to nutrition and physical activity.

Design, Setting, and Participants: This crosssectional, qualitative study included individual interviews with 30 childcare teachers and directors. Interviews were conducted from fall 2014 through spring 2015. All interviews were digitally recorded and audio files were transcribed. Transcripts were independently coded by three researchers using NVivo software, then analyzed for themes.

Outcome Measures and Analysis: All participants were women, $57 \%$ were Caucasian, $70 \%$ worked full time in childcare, and 39\% had 1-5 years' experience with young children (2-5 years).

Results: Four themes emerged from the interviews: teachers perceive their role in cognitive and social development and being a good citizen but not necessarily health habits, 